\title{
The Impacts of Sprawl on Biodiversity: the Ant Fauna of the Lower Florida Keys
}

\author{
$\underline{\text { Elizabeth A. Forys }}^{1}$ and $\underline{\text { Craig R. Allen }}^{2}$
}

\begin{abstract}
Sprawling development can affect species composition by increasing the rate of invasion by non-native species, and decreasing the persistence of native species. This paper briefly reviews the scientific literature on the impacts of sprawl on biological diversity, with specific emphasis on the influence of sprawl on non-native species richness. We then explore the relationship between sprawl and biodiversity using a data set of ant species collected from 46 habitat patches located in the increasingly suburbanized Florida Keys, USA. We quantified sprawl as the proximity of roads and amount of development surrounding a habitat patch. Using bait transects, we identified 24 native and 18 non-native species of ants. Neither the overall number of native species nor the number of rare native species were significantly affected by the amount of development or proximity to roads, however, the number of non-native species was significantly correlated with the amount of development. Surprisingly, the number of native species and rare native species was significantly positively correlated with the number of non-native species. Areas that supported many species of native ants also supported a diverse non-native ant fauna, and the species distribution was highly nested. Currently, the native ant fauna of the Florida Keys does not appear to be dramatically influenced by sprawl, however, if development increases, the number of non-native ants may increase, and many of these species have been documented as decreasing native ant diversity. If development plateaus, there is evidence that the native ant fauna could persist and could decrease non-native species richness through competition or predation.
\end{abstract}

Key Words: extinctions; exurban development; Florida; invasions; nestedness; sprawl

\section{INTRODUCTION}

Much urban and suburban growth in the past 50 years may best be characterized by a lack of centralized planning: growth patterns generated by transportation, water, and sewer networks, and by a mismatch between jurisdictional scales and planning needs (Conroy et al. 2003). The result of this haphazard development has commonly been called "sprawl" or "exurban development," and its growth is accelerating in many areas. Since 1980, suburban populations of major cities in the U.S. have grown ten times faster than central city populations (Benfield et al. 1999). More than 16\% of development that has ever occurred in the U.S. happened between 1982 and 1992 (Lassila 1999).
The costs of this lack of local, regional, and national planning are many. Several articles that directly address other effects of sprawl on humans or nature can be found in this issue of Ecology and Society (formerly known as Conservation Ecology). Our paper is primarily concerned with the impacts of sprawl on biological diversity, with a specific emphasis on the mechanisms that are leading to biological homogenization. After a brief literature review, we examine some of the leading theories on the effects of sprawl on biodiversity using the ant fauna of the Florida Keys. We define sprawl as including both the building of roads and disturbance of habitat for human dwellings, businesses, and recreational areas. 


\section{Impacts of Urban Sprawl on Biodiversity: a Literature Review}

Habitat destruction is the primary cause behind the extinction of most terrestrial species (Baillie and Groombridge 1996), but the impact of human development or roads may be far greater than the immediate area of the habitat loss (Forman 2002). The reason why sprawl is such a threat to biodiversity is not simply because of the amount of habitat that is directly converted to a road or a building, but the effects these human disturbances have on the larger landscape.

Many animals simply avoid areas with even moderate human densities or activity levels. For example, deer may avoid areas as far as $1.6 \mathrm{~km}$ away from developed areas (Vogel 1989). Decreased habitat quality caused by sprawl also may exclude animals. This is documented for aquatic organisms (Kemp and Spotila 1997), where the mechanisms behind decreased habitat quality include greater variation in stream flows, hypoxia (Limburg and Schmidt 1990) and siltation (Chapman 1988). Animal activity patterns reflect an evolved adaptation to ecological pattern and structure. Animal activity patterns can be altered with changes in land use associated with sprawl. For example, coyote (Canis latrans) movement activity patterns shift in suburban areas, becoming more nocturnal - "an external modification of internally derived diel patterns;" as well, in suburban areas, the amplitude of coyote circadian rhythms may increase (McClennen et al. 2000).

Changing land use and land cover introduces new barriers and corridors for animal movements, and fragments existing matrix land covers. Barriers to animal movement range from roadways and inappropriate habitats to literal barriers, such as chain link fences. These barriers block migratory movements and dispersal within populations. Road building is a major contributor to the creation of barriers to animal movement. Roads themselves may become population sinks for some animal species (Fahrig et al. 1995, Forman 2002). Corridors and fragmentation also alter animal movements. Decreased connectivity results in increased isolation of populations that may lead to the loss of population viability and genetic diversity (Lande and Shannon 1996, Hale et al. 2001). The presence of humans may increase the movement of animals, increasing their vulnerability to predation, and decreasing survival in other ways, for example by decreasing the amount of time spent foraging and resting (Taylor and Knight 2003).

Of these potential negative effects that roads and developments can have on native ecosystems, the increase in invasive, non-indigenous species in the surrounding area has been shown to be one of the greatest (Elton 1958, Simberloff 1981, Rejmánek 1989). Human disturbance is related to biological invasions and extinctions through three, potentially non-exclusive pathways. By human disturbance, we mean the alteration of natural habitat by mowing, paving, farming, logging, damming, and building. First, disturbance can provide habitat with reduced native predators and competitors for species that are human commensals or early successional species (disturbance $\Rightarrow$ extinctions $\Rightarrow$ invasions)(Diamond and Veitch 1981, Williamson 1996). Second, disturbance can act as a dispersal corridor, increasing the rate of invasion into undisturbed ecosystems (Tyser and Worley 1992, Forman 1995). Once established, some non-indigenous species have a dramatic negative influence on communities (Simberloff 1981) and ecosystems (Vitousek 1990, Vitousek et al. 1996)(disturbance $\Rightarrow$ invasions $\Rightarrow$ extinctions). Or, disturbance can alter ecological structure directly or prevent the spread of contagious structuring processes, thus altering the availability of resources and energy, and this may lead to simultaneous events of invasion and extinction (disturbance $\Rightarrow$ invasions $\Leftrightarrow$ extinctions $\Leftarrow$ disturbance)(Allen et al. 1999).

Many of these changes directly or indirectly affect species composition. The diversity of native species of birds is negatively related to the amount of nonnative vegetation (Mills et al. 1989). There are more, and a larger proportion of, invasive species in developed areas than in undeveloped areas, and this is true for both plants and animals (e.g., Hobbs 1988, Rudnicky and McDonnell 1989). It is equally true in aquatic systems, where large differences in community composition and richness have been documented between urban and non-urban watersheds, with urban watershed dominated by pollution-tolerant species (Kemp and Spotila 1997). Species composition of birds and mammals differs between developed areas and undeveloped areas, with cats and dogs more abundant and foxes and coyotes less abundant in developed areas, and a similar change in the bird community, with "humanadapted" species more abundant closer to development (e.g., House Wren, Troglodytes aedon, Brown-headed Cowbird, Molothrus ater, and 
American Robin, Turdus migratorius)(Odell and Knight 2001). Increases in these cosmopolitan native and non-native species and concurrent decreases in populations of many rare and specialized endemics may ultimately lead to increasing homogenization of our biota.

\section{Impact of Sprawl on the Ant Fauna of the Florida Keys}

The Lower Florida Keys is the terminal portion of an archipelago of islands extending westward from the mainland of Florida, USA. Subtropical in climate, the Lower Keys is a unique ecosystem that supports a diverse community of endemic flora and fauna. The southernmost of the Keys, Key West, was urbanized in the 1800 s, but road building and development in the remainder of the Lower Keys have mainly occurred in the past 20-50 years (Davis and Ogden 1994). Most of this development is in the form of subdivisions, and there is no public transportation on any of the Lower Keys except Key West. Surrounding and intermingling these developments are publicly owned parcels of land, including a U.S. Fish and Wildlife Refuge.

The ants of the Florida Keys have been surveyed by both Wilson (1964) and Deyrup et al. (1988). Most species are biogeographically Antillian in origin, but a number are from the southeastern coastal plain. During a somewhat limited survey of four of the largest keys, Wilson found 30 species in the 1950s, including eight non-native species. In the 1980s, Deyrup and colleagues (1988) performed an indepth survey of most of the Keys using a variety of methods. They identified 83 species, including 27 non-natives. It is possible that some of these nonnatives were present when Wilson did his survey, but Deyrup believed that many had recently colonized. At the time of the Deyrup et al. (1988) survey, there was no evidence that the non-natives were displacing any native species.

We used the ant fauna of the Florida Keys to explore the relationships between the amount of sprawl and species richness and biological homogenization because of the large proportion of non-native ants, the recentness of development and sprawl, and the wide range of density of sprawl throughout the Lower Keys. Specifically we looked at:

1. The relationship between sprawl and the species richness of native ants and non-native ants within a habitat patch.

2. The relationship between the amount of sprawl and the presence of rare native ant species.

\section{METHODS}

\section{Ant Collection}

Ant species composition was determined by sampling in habitat patches $(>0.10 \mathrm{ha})$ of the two most common habitat types (transitional salt marsh, hardwood hammock) on all 12 of the Lower Keys that are reachable by road and have some development (Fig. 1). Transitional salt marsh typically occurs at 3-5 m above sea level between mangroves and the upland hardwood hammocks. The dominant tree species is buttonwood (Conocarpus erectus) and the understory is composed of marsh grasses and sedges. Hardwood hammocks occur upland of transitional salt marsh and are closed-canopy, broadleaved forests that have a high diversity (>150 species) of both evergreen and semi-evergreen tropical tree species.

We defined a patch as being a contiguous area of our specific habitat as was defined using photointerpretation of aerial photography. Originally, we planned on sampling three sites of each habitat type on each key, but on several of the smaller keys there were $<3$ patches of each habitat type and so there were fewer sites on these keys. Traveling from west to east, we sampled on Key West (1 salt marsh site, 1 hammock site), Stock Island $(0,1)$, Boca Chica $(3,3)$, Saddlebunch/Sugarloaf Key $(3,3)$, Cudjoe $(3,3)$, Ramrod (2, 1), Summerland (2, 2), Little Torch $(1,1)$, Middle Torch (1,1), Big Torch $(3,3)$, Big Pine (3, 3), and No Name $(1,1)$ Keys (Fig. 1).

Ant bait transects were established on undeveloped lands using randomly chosen Universal Transverse Mercator coordinates within the habitat patch as the starting point and a random number table to determine the orientation of the transect. Twentythree of the transects were placed in transitional salt marsh and 23 were placed in hardwood hammock. Each transect was $90 \mathrm{~m}$ long and consisted of ten stations of paired baits (one honey, one meat, 45- 
Fig. 1. Map of the Lower Florida Keys showing sampling locations. Lines between Keys indicate groupings of Keys used in analyses.

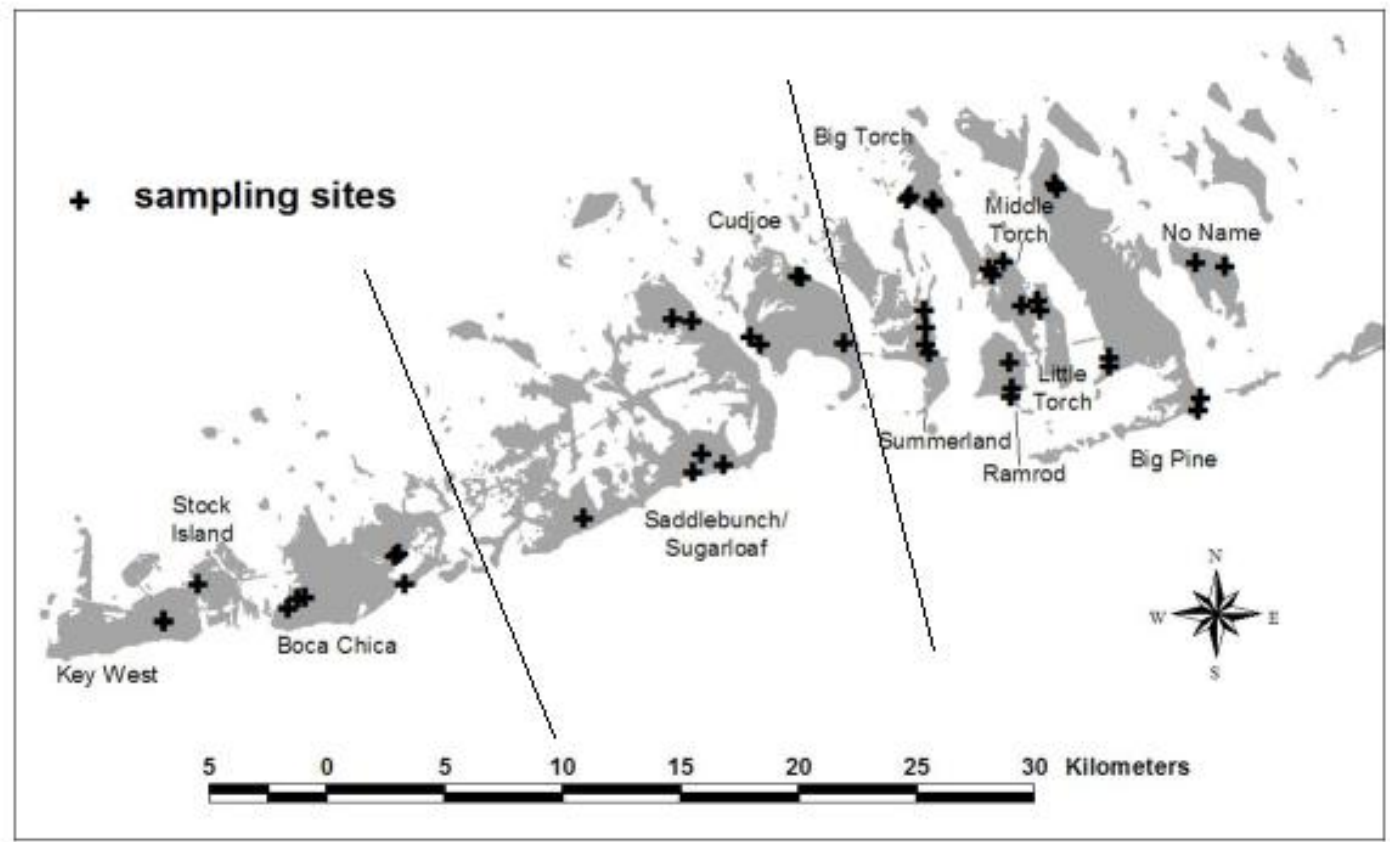

$60 \mathrm{~cm}$ apart) placed $10 \mathrm{~m}$ apart on the ground (Wojcik 1994). Each bait transect was sampled once during a 2 -week period from 15-31 July 1996 in the morning (0700-1000 h) or the afternoon (1600$1900 \mathrm{~h})$ when temperatures were favorable for fire ant foraging. After placement, baits were left out for $1.5 \mathrm{~h}$ to attract ants; then, they were collected, placed in cups, frozen, and transported to the Imported Fire Ant Laboratory (Gainesville, Florida, USA). In the laboratory, ants were picked from the bait, placed in alcohol, and identified to species. Determining species composition using baits will miss some species that are not attracted to the baits, or that do not forage on the ground; however, these differences are constant throughout all the study sites. Baits cannot be used to determine relative abundance of each species, because of differences in the way a species forages. Thus, our baits were used to determine which species were present, not how abundant each species was at a habitat patch. 


\section{Estimation of Independent Variables}

We quantified the degree of sprawl at each habitat patch by estimating the influence of paved roads and development in the vicinity of the patch. We used the Euclidean (shortest) distance of the closest portion of the bait transect to a paved road, and the amount of development in the $150-\mathrm{m}$ radii surrounding each transect to approximate the influence of sprawl on the ant composition of the transect. A previous study had found that these two variables significantly predicted the presence of one of the more common and influential non-native ant species, Solenopsis invicta (red imported fire ant) (Forys et al. 2002). We measured these two variables using habitat and road data sets analyzed using the ARC/INFO geographic information system (GIS) software (Environmental Systems Research Institute 1990, Forys et al. 2002).

Habitat data (including types of human developments) came from the Advanced Identification project mapping coverages provided by the Environmental Protection Agency (EPA, Region IV, Atlanta, Georgia). These vector-based coverages were created by digitizing habitats based on photo-interpretation and ground truthing. The photographs were taken in 1994 and ground truthing occurred in 1995-1996. In some cases, the ground truthing occurred concurrently with our ant data collection. The minimum resolution of the GIS coverages was approximately 0.10 ha. To estimate the influence of human development, we selected all areas in the habitat coverage that had been classified as "developed" by the habitat map. Developed areas included buildings, parking lots, and highly disturbed yards $>0.10$ ha. Road data came from Florida Department of Transportation vector-based coverages. To prepare these vectorbased map coverages for analysis, we converted them to raster-based maps using the GRID module of ARC/INFO. We used a 10 x $10 \mathrm{~m}$ cell for all raster maps.

We measured several other regional-level variables that might potentially have an influence on ant species richness within a habitat patch. Patch area and perimeter were measured using the vectorbased coverages described above. Patch edge was measured by dividing a patch's area by its perimeter. For the purposes of this study, we did not measure local-level variables within each habitat patch, such as tree diversity or ground cover, because we were most concerned with large-scale differences in native and non-native species richness caused by roads and development, and not specific differences about which species occurred in each patch.

\section{Data Analysis}

Unless specified, all of the analyses were done using SPSS, ver. 11.5 (SPSS Inc., Chicago, Illinois, USA), and in all cases, continuous variables were tested for normality before analysis and were transformed if the assumptions were violated. If data could not be transformed, a non-parametric test was conducted.

At each site, an ant species was said to be present if it was found in one of the ten bait traps used at that site. Species richness at each site was determined by summing the number of ant species present. A native ant species was said to be rare if it was present at $<10 \%$ of all sites.

Before exploring the influence of sprawl on ant biodiversity, we looked at how total native species richness was related to non-native species richness, the overall pattern of ant diversity among sites, and how richness varied with other regional-level variables. We then repeated this analysis using the species richness of rare ant species present.

Total and rare native species richness was compared with non-native species richness using correlation analyses. Then, we examined the overall pattern of diversity of ant species among sites to see whether it had a nested or more random subset structure. A nested subset structure of occurrences is one in which the taxa present in species-poor assemblages are also found in increasingly species-rich assemblages (Atmar and Patterson 1993). This pattern can reflect either the differential dispersal ability of taxa (Lomolino 1996) or their extinction in an orderly sequence (Wright et al. 1998). We tested the presence-absence matrix for a nested subset structure by the method of Atmar and Patterson (1993), using their matrix temperature statistic, which provides a standardized measure of matrix disorder. In a perfectly nested matrix, $T=0$, whereas in a system where all species occur at random, $T=100$. The statistical significance of the observed $T$ value was determined by Monte Carlo simulation done 5000 times using the Nestedness Temperature Calculator (Atmar and Patterson 1993). 
Next, we determined the association between total native, rare native, and total non-native species richness compared with non-sprawl regional-level variables (habitat type, Key the site occurred on, patch area, edge around patch). We tested the association of the categorical variables (habitat type and Key) using a two-way analysis of variance (ANOVA). One challenge was that, at several of the Keys, we were only able to sample a few sites because of the paucity of available habitat; therefore, we lacked the sample size necessary to carry out the ANOVA using all 12 Keys. In addition, what humans have named a "Key" is often a collection of many small islands that are not linked by land. To satisfy the assumptions of the ANOVA, and still determine whether species richness was related to particular Keys that we sampled, we decided to pool the sites into three groups. The Lower Florida Keys are approximately $50 \mathrm{~km}$ from the western tip of Key West to the eastern tip of No Name Key , and we divided the Keys into three groups based on linear west-east distance (Fig. 1). Our first group of sites comprised those that occurred on Key West, Stock Island, and Boca Chica (17 km from west to east). Our second group included Saddlebunch/Sugarloaf Keys and Cudjoe $(17 \mathrm{~km})$; our third group included Ramrod, Summerland, the Torch Keys, Big Pine Key, and No Name Keys $(16 \mathrm{~km})$.

Finally, we explored the relationships between total native ant, rare native ant, and non-native ant species richness and continuous variables (patch area, edge, Euclidian distance to roads, amount of development around a patch) using correlation coefficients. Variables exhibiting high correlations were also included in the calculation of partial correlation coefficients. Significant partial correlations suggest that the correlation between two particular variables exists independent of the other variables included in the analysis.

\section{RESULTS}

We identified 24 native and 18 non-native species of ants at the 46 transects (Figs. 2 and 3 ). The number of native species at a habitat patch ranged from 110 and the number of non-natives from $0-9$. The overall species richness ranged from 1-13. Some of the ant species were present at a large proportion of the sites, whereas others were only present at one or two sites. Nine of the native ant species were relatively common, and were found at $8-31$ of the sites. The remaining nine native ant species were only found at four or fewer sites, and these were designated "rare" species. These species all have been labeled as rare in the Florida Keys by other sources (see Deyrup et al. 1998, 2000). The most abundant non-native species was Paratrechina longicornis, which was present at 28 sites. Seven non-native species were found at only one or two sites (Fig. 3).

Surprisingly, total native ant and non-native ant species richness was nearly significantly positively correlated $(R=0.286, p=0.054)$, and rare native ant and non-native ant species richness was significantly positively correlated $(R=0.753, p<$ 0.001, Fig. 4). In addition, we looked at the correlation between "common" native ant richness (i.e., the ants present at $>10 \%$ of the sites) and nonnative ant species richness, and this was highly correlated as well $(R=0.777, p<0.001$, Fig. 4$)$.

Habitat patches that had many species of native ants (either common or rare) tended to have more nonnative species. Similarly, species distribution patterns were significantly nested when all of the native and non-native species were put into the presence-absence matrix $(T=14.8, p=2.32 \times$ 10-21) and when only native species were considered $(T=13.3, p=1.05 \times 10-13)$.

None of the relationships among total native ant species richness, rare native ant species richness, or non-native ant species richness, and Key or habitat was found to be significant (Table 1). There was no evidence that native species richness (both total and rare) was influenced by the amount of sprawl. Total native and rare native species richness were not significantly correlated with the size of a habitat patch, the amount of edge of the patch, the amount of development near the patch, or the proximity of a road $(p>0.05$, Table 1$)$.

There was evidence that non-native species richness was influenced by sprawl. Non-native species richness was significantly correlated with the amount of development, but not the size of a habitat patch, the amount of edge of the patch, or the proximity of a road ( $p>0.05$, Table 2$)$. 
Fig. 2. The number of sites in the Lower Florida Keys that had each native species present.

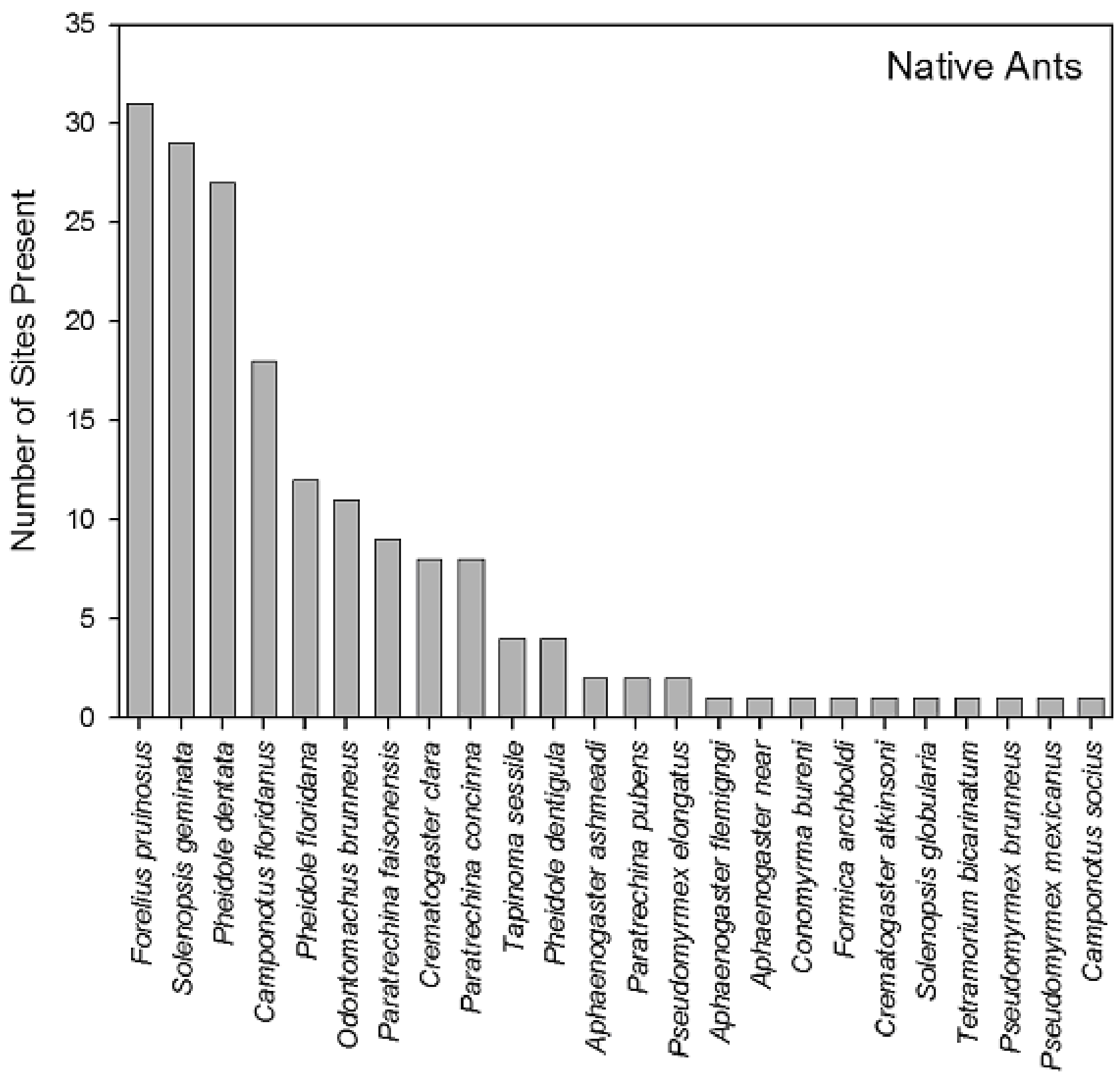

Ant Species 
Fig. 3. The number of sites in the Lower Florida Keys that had each non-native species present.

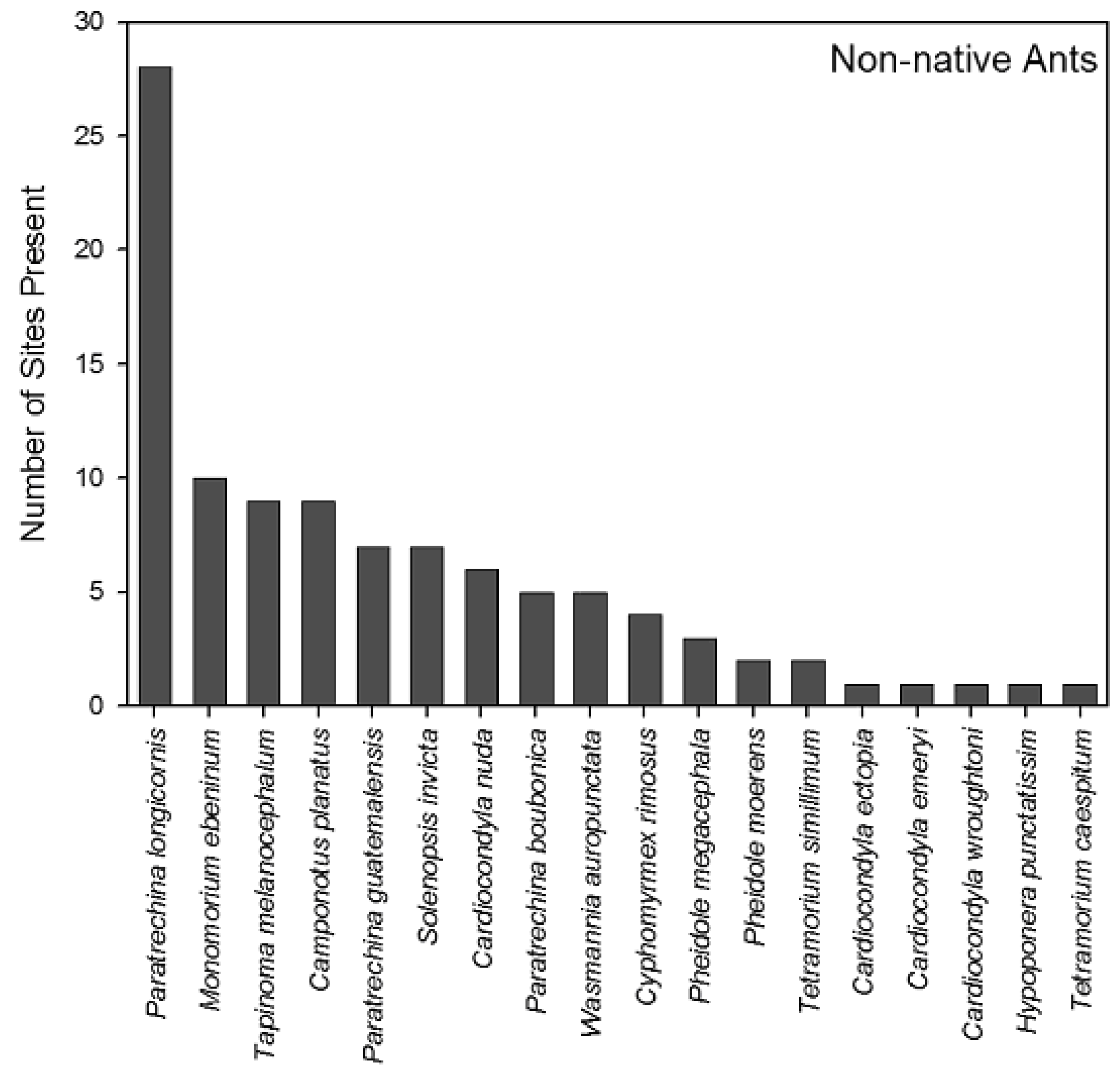

Ant Species 
Fig. 4. Scatterplots of the number of common native and rare native species of ants compared with the number of non-native ants at 46 habitat patches in the Lower Florida Keys. Both relationships were highly significant $(p<0.001)$.

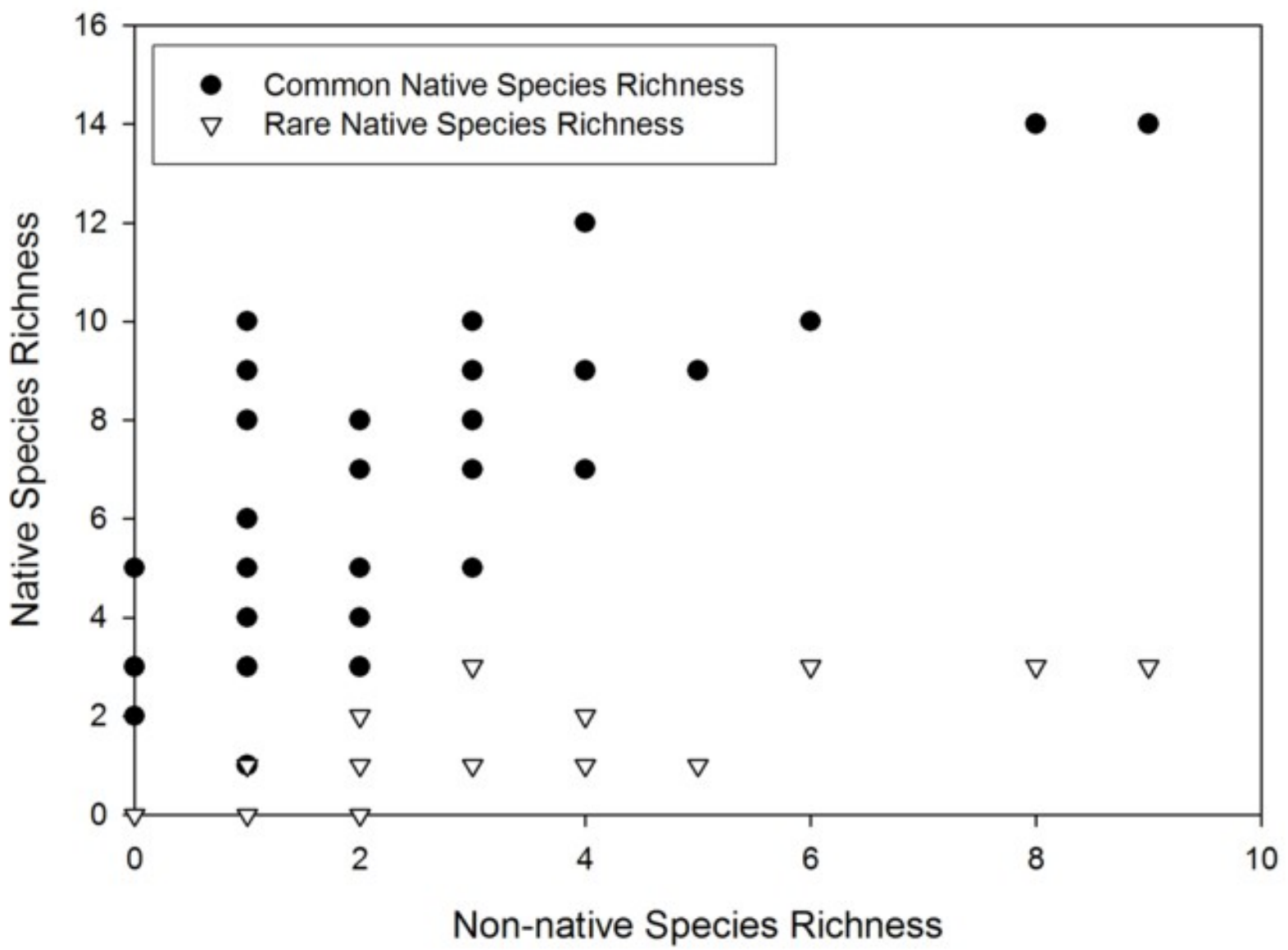

\section{DISCUSSION}

Currently, native ant species richness does not appear to be related to suburban sprawl in the Florida Keys. Neither the total number of native ant species nor the number of unique, rare ant species were significantly affected by either the presence of roads or development.

The distribution of both native and non-native species appears to be highly nested. This is surprising because most of the non-natives appear to have colonized only recently. One explanation for this pattern is that species occurrence is related to the dispersal ability of the ant species (Atmar and Patterson 1993). Some patches may be closer to other source patches, and this also explains why patches with more non-natives tended to have more natives. An alternative explanation is that some patches are simply better places for ants in terms of habitat. Both these explanations are supported by the nearly significant and significant positive correlations between the number of native and rare native ant species and the number of non-native species. 
Table 1. Results of two-way ANOVAs that tested the influence of habitat type and key on the number of total native species, rare native species, and non-native species at each site in the Lower Florida Keys

\begin{tabular}{lccc}
\hline \hline Component of 2-way ANOVA & $F$ & $p$ & d.f. \\
\hline Total native species richness_habitat & 0.075 & 0.075 & 1 \\
Total native species richness_Key & 1.747 & 0.187 & 2 \\
Total native species richness_habitat x Key & 0.086 & 0.917 & 2 \\
Rare native species richness_habitat & 0.531 & 0.560 & 1 \\
Rare native species richness_Key & 0.430 & 0.599 & 2 \\
Rare native species richness_habitat x Key & 1.031 & 0.366 & 2 \\
Total non-native species richness-habitat & 0.507 & 0.481 & 1 \\
Total non-native species richness-Key & 0.797 & 0.458 & 2 \\
Total non-native species richness-habitat x Key & 0.116 & 0.889 & 2 \\
\hline
\end{tabular}

Several recent studies (Levine and D'Antonio 1999, Stohlgren et al. 1999) have also recorded a positive correlation between species richness of native and non-native species, including a study of ants in north-central Florida (Morrison and Porter 2003). In these other studies, it was inferred that the positive correlations resulted from biotic or abiotic factors that similarly influenced both native and non-native species.

Even though native and non-native species richness was nearly significantly correlated, non-native species richness was significantly increased by the amount of development, whereas native species richness was not related to development or roads. In the long term, this may mean that the number of non-native ant species may increase as development increases, and the potential for a negative effect on the native species exists because they tend to occur together. Some of the non-native species found at our sites are known to have an impact on native ant species elsewhere, particularly in areas where the non-natives have been established for long periods of time ( $>20$ years). The most common non-native ant found in our study, the crazy ant (Paratrechina longicornis), is a scavenger ant that primarily feeds on the sugary excretions produced by Homoptera (scale insects and mealybugs). It has been associated with the decline of native ant species in a wide variety of places, from Biosphere 2 in Arizona
(Wetterer et al. 1999) to the Dry Tortugas (islands that are relatively near the Florida Keys, Hölldobler and Wilson 1990). The red imported fire ant, Solenopsis invicta, has been associated with the decline of many species of native ants (see Wojcik 1994). Although the red imported fire ant colonized the Keys relatively recently (in the mid 1980s), it is currently found in disturbed areas on most of the Keys (Forys et al. 2002) and at seven (five buttonwood, two hardwood hammock) of the intact habitat patches sampled in this survey. The little fire ant, Wasmannia auropunctata, was found at only five of the sites, but may have increased its range since the 1980s (Deyrup et al. 1988). It is associated with the decline of native ant species in areas such as the Galapagos Islands (Clark et al. 1982). The big-headed ant, Pheidole megacephala, is a predaceous ant native to southern Africa that is associated with declines in ant species richness throughout the subtropics and tropics (Hoffmann et al. 1999). Historically, it has not dominated the ant fauna in Florida (Deyrup et al. 2000), and it was only found at three of our sites, but it may have the potential to expand in the Florida Keys. Several other species of non-native ants are aggressive foragers and may be directly competing with native ants.

However, if development does not increase substantially in the next few years, it is possible that 
Table 2. Relationships among continuous habitat variables, and species richness estimated at habitat patches in the Lower Florida Keys. The upper number is the Correlation coefficient and the lower number (shown in parentheses) is the significance probability. The bolded numbers indicate a significant $(p<0.05)$ result.

\begin{tabular}{lllllll}
\hline \hline & Edge & $\begin{array}{l}\text { Amount of } \\
\text { Development }\end{array}$ & $\begin{array}{l}\text { Distance to } \\
\text { Roads }\end{array}$ & $\begin{array}{l}\text { Total Native } \\
\text { Richness }\end{array}$ & $\begin{array}{l}\text { Rare Native } \\
\text { Richness }\end{array}$ & $\begin{array}{l}\text { Non-native Ri- } \\
\text { chness }\end{array}$ \\
\hline Area & $\mathbf{0 . 7 8 2}$ & $\mathbf{- 0 . 3 2 2}$ & -0.0512 & -0.0170 & 0.0148 & -0.0409 \\
& $(\mathbf{0 . 0 0 1 )}$ & $\mathbf{( 0 . 0 2 9 )}$ & $(0.736)$ & $(0.911)$ & $(0.922)$ & $(0.787)$ \\
Edge & & $\mathbf{0 . 3 8 8}$ & 0.127 & 0.075 & 0.132 & -0.097 \\
& & $\mathbf{( 0 . 0 0 8 )}$ & $(0.399)$ & $(0.619)$ & $(0.381)$ & $(0.523)$ \\
Amount of & & -0.229 & 0.097 & 0.161 & $\mathbf{0 . 3 3 0}$ \\
Development & & $(0.126)$ & $(0.522)$ & $(0.286)$ & $\mathbf{( 0 . 0 2 5 )}$ \\
Distance to Roads & & & -0.012 & 0.231 & 0.206 \\
& & & $(0.935)$ & $(0.123)$ & $(0.169)$ \\
Total Native & & & & & $\mathbf{0 . 3 4 2}$ & $\mathbf{0 . 2 8 6}$ \\
Richness & & & $(\mathbf{0 . 0 2 0})$ & $\mathbf{( 0 . 0 5 4 )}$ \\
Rare Native & & & & & $\mathbf{0 . 7 4 3}$ \\
Richness & & & & & $(<0.001)$ \\
\hline
\end{tabular}

the native ant communities may be capable of remaining intact despite the presence of invasive non-native ants. Many of the non-native species in the Florida Keys have invaded in the past 20 years (Deyrup et al. 1988). A recent study (Morrison 2002) conducted in Texas found that 12 years after documenting a decline in species richness and abundance of native ants caused by an invasion by red imported fire ant, the native ant community had returned to the observed pre-invasion level. Native ants have been documented preying on and outcompeting even aggressive non-native species (Rao and Vinson 2004).

Although the Florida Keys have been extensively developed during the past 20 years, this development has been somewhat countered by habitat protection efforts by both the federal and state governments. Much of this protected land is relatively small in area, however, the size of the habitat patches that we sampled were very large relative to the body size of our study organisms. Larger native taxa, such as vertebrates, are more likely to be directly affected by the scale of humancaused disturbance and fragmentation in the Lower Florida Keys, and other relationships among disturbance, invasion, and extinction may be evident. For the native ant fauna of the Florida Keys and other arthropod communities, even modest controls on the amount of sprawl may help preserve biodiversity.

Responses to this article can be read online at: http://www.ecologyandsociety.org/vollo/iss 1/art25/responses/

\section{Acknowledgments:}

This project was funded by the Florida Game and Fresh Water Fish Commission's Nongame Wildlife Program. B. Stieglitz and R. Skinner helped us by providing access and timely permits to refuge and State-owned land. P. Frank and S. Klett provided input on study design. D. Wojcik, J. Sullenger, and B. Mayfield sorted and identified all of the ants. The South Carolina Cooperative Fish and Wildlife Research Unit is jointly supported by a cooperative agreement between the U.S. Geological Survey, the South Carolina Department of Natural Resources, Clemson University, and the Wildlife Management Institute. 


\section{LITERATURE CITED}

Allen, C. R., E. A. Forys, and C. S. Holling. 1999. Body mass patterns predict invasions and extinctions in transforming landscapes. Ecosystems 2:114-121.

Atmar, W., and B. D. Patterson. 1993. The measure of order and disorder in the distribution of species in a fragmented habitat. Oecologia 96:373382.

Baillie, J., and B. Groombridge. 1996. 1996 IUCN red list of threatened animals. World Conservation Union (IUCN), Gland, Switzerland.

Benfield, F. K., M. D. Raimi, and D. D. T. Chen. 1999. Once there were greenfields. Natural Resources Defense Council, New York, New York, USA.

Clark, D. B., Guayasamin, O. Pizamino, C. Donoso, and Y. Paez de Villacis. 1982. The tramp ant Wasmannia auropuncata: autecology and effects of ant diversity and distribution on Santa Cruz Island, Galapagos. Biotropica 14:196-207.

Chapman, D. W. 1988. Critical review of variables used to define effects of fines in redds of large salmonids. Transactions of the American Fisheries Society 117:1-21.

Conroy, M. J., C. R. Allen, J. T. Peterson, L. J. Pritchard, and C. T. Moore. 2003. Landscape change in the southern Piedmont: challenges, solutions, and uncertainty across scales. Conservation Ecology 8(2):3. [Online.] URL:

http://www.consecol.org/vol8/iss2/art3/.

Davis, S. M., and J. C. Ogden. 1994. Everglades: the ecosystem and its restoration. St. Lucie Press, Delray Beach, Florida, USA.

Deyrup, M. A., N. Carlin, J. Trager, and G. Umphrey. 1988. A review of the ants of the Florida Keys. Florida Entomologist 71:163-176.

Deyrup, M. A., L. Davis, L. Cover, and S. Cover. 2000. Exotic ants in Florida. Transactions of the American Entomological Society 126:293-326.

Diamond, J. M., and C. R. Veitch. 1981. Extinctions and introductions in the New Zealand avifauna: cause and effect? Science 211:499-501.
Elton, C. S. 1958. The ecology of invasions by animals and plants. Methuen, London, UK.

Fahrig, L., J. H. Pedlar, S. E. Pope, P. D. Talyor, and J. F. Wegner. 1995. Effect of road traffic on amphibian density. Biological Conservation 15:177-182.

Environmental Systems Research Institute (ESRI). 1990. ARC/INFO user's guide. ESRI, Redlands, California, USA.

Forman, R. T. T. 1995. Land mosaics: the ecology of landscapes and regions. Cambridge University Press, Cambridge, UK.

Forman, R. T. T. 2002. Road ecology: science and solutions. Island Press, Washington, D.C., USA.

Forys, E. A., C. R. Allen, and D. P. Wojcik. 2002. Distribution of the red imported fire ant in the Lower Florida Keys: effects of human development and roads and spatial overlap with vulnerable rare species. Biological Conservation 108:27-33.

Hale, M. L., P. W. W. Lurz, M. D. F. Shirley, S. Rushton, R. M. Fuller, and K. Wolff. 2001. Impact of landscape management on the genetic structure of red squirrel populations. Science 293:22462248.

Hobbs, E. 1988. Using ordination to analyze the composition and structure of urban forest islands. Forest Ecology and Management 23:139-158.

Hoffmann, B.D., A. H. Andersen, and G. J. E. Hill. 1999. Impact of an introduced ant on native rain forest invertebrates: Pheidole megacephala in monsoonal Australia. Oecologia 120:595-604.

Hölldobler, B., and E. O. Wilson. 1990. The ants. Belknap Press of Harvard University Press, Cambridge, Massachussetts, USA.

Kemp, S. J., and J. R. Spotila. 1997. Effects of urbanization on brown trout Salmo trutta, other fishes and macroinvertebrates in Valley Creek, Valley Forge, Pennsylvania. American Midland Naturalist 138:55-68.

Lande, R., and S. Shannon. 1996. The role of genetic variation in adaptation and population persistence in a changing environment. Evolution 
50:434-437.

Lassila, K. D. 1999. The new suburbanites: how American plants and animals are threatened by sprawl. Amicus Journal 21:16-20.

Levine, J. M., and C. M. D’Antonio. 1999. Elton revisited; a review of evidence linking diversity and invasibility. Oikos 87:15-26.

Limburg, K. E., and R. E.Schmidt. 1990. Patterns of fish spawning in Hudson River tributaries: response to an urban gradient? Ecology 71:12381245.

Lomolino, M. V. 1996. Investigating causality of nestedness of insular communities: selective immigrations or extinctions? Journal of Biogeography 23:699-703.

McClennen, R., R. Wigglesworth, and S. H. Anderson. 2000. The effect of suburban and agricultural development on the activity patterns of coyotes (Canis latrans). The American Midland Naturalist 146:27-36.

Mills, G. S., J. B. Dunning, Jr., and J. M. Bates. 1989. Effects of urbanization on breeding bird structure in southwestern desert habitats. Condor 91:416-428.

Morrison, L. W. 2002. Long-term impacts of an arthropod-community invasion by the imported fire ant, Solenopsis invicta. Ecology 83:2337-2345.

Morrison, L. W., and S. D. Porter. 2003. Positive association between densities of the red imported fire ant, Solenopsis invicta (Hymenoptera: Formicidae), and generalized ant and arthropod diversity. Environmental Entomology 32:548-554

Odell, E. A., and R. L. Knight. 2001. Songbird and medium-sized mammal communities associated with exurban development in Pitkin County, Colorado. Conservation Biology 15:1143-1150.

Rao, A., and S. B. Vinson. 2004. Ability of resident ants to destruct small colonies of Solenopsis invicta (Hymenoptera: Formicidae). Environmental Entomology 33: 587-598.

Rejmánek, M. 1989. Invasibility of plant communities. Pages 369-388 in J. A. Drake, H. A. Mooney, F. di Castri, R. H. Groves, F. J. Kruger,
M. Rejmánek, and M. Williamson, editors. Biological invasions, a global perspective. John Wiley, Chichester, UK.

Rudnicky, J. L., and M. J. McDonnell. 1989. Forty-eight years of canopy change in a hardwoodhemlock forest in New York City. Bulletin of the Torrey Botanical Club 116:52-64.

Simberloff, D. E. 1981. Community effects of introduced species. Pages 53-81 in M. H. Nitecki, editor. Biotic crises in ecological and evolutionary time. Academic Press, New York, New York, USA.

Stohlgren, T. J., D. Binkley, G. W. Chong, M. A. Kalkhan, L. D. Schell, K. A. Bull, Y. Otsuki, G. Newman, M. Bashkin, and Y. Son. 1999. Exotic plant species invade hot spots of native plant species diversity. Ecological Monographs 69:25-46.

Taylor, A. R., and R. L. Knight. 2003. Wildlife responses to recreation and associated visitor perceptions. Ecological Applications 13:951-963.

Turner, M. G., D. N. Wear, and R. O. Flamm. 1996. Land ownership and land-cover change in the southern Appalachian Highlands and the Olympic Peninsula. Ecological Applications 6:1150-1172.

Tyser, R. W., and C. A. Worley. 1992. Alien flora in grasslands adjacent to road and trail corridors in Glacier National Park, Montana (USA). Conservation Biology 6:253-262.

Vitousek, P. M. 1990. Biological invasions and ecosystem processes: towards an integration of population biology and ecosystem studies. Oikos 57:7-13.

Vitousek, P. M., C. M. D'Antonio, L. L. Loope, and R. Westbrooks. 1996. Biological invasions as global environmental change. American Scientist 84:468-478.

Vogel, W. O. 1989. Response of deer to density and distribution of housing in Montana. Wildlife Society Bulletin 17:406-413.

Wetterer, J. K., S. E. Miller, D. E. Wheeler, C. A. Olson, D. A. Pohemus, M. Pitts, I. W. Ashton, A. G. Himler, M.M. Yospin, K. R. Helms, E. L. Harken, J. Gallaher, C. E. Dunning., M. Nelson, J. Litsenger, A. Southern, and T. L. Burgess. 1999. Ecological dominance by Paratrechina longicornis 
(Hymentoptera: Formicidae), an invasive tramp ant, in Biosphere 2. Florida Entomologist 82:381-388.

Williamson, M. 1996. Biological invasions. Chapman and Hall, London, UK.

Wilson, E. O. 1964. The ants of the Florida Keys. Breviora 210:1-14.

With, K. A. 2002. The landscape ecology of invasive spread. Conservation Biology 16:11921203.

Wojcik, D. P. 1994. Impact of the red imported fire ant on native ant species in Florida. Pages 269-281 in D. F. Williams, editor. Exotic ants: biology, impact, and control of introduced species. Westview Press, Boulder, Colorado, USA.

Wright, D. H., B. D. Patterson, G. M. Mikkelson, A. Cutler, and W. Atmar. 1998. A comparative analysis of nested subset patterns of species composition. Oecologia 113:1-20. 